\title{
Sustenance: Determining the Factors for Prediction and Prediction of the Customers Willing to Wait to Shop Grocery
}

\author{
R. Ayyamperumal, B. Senthil Arasu
}

\begin{abstract}
In the fast moving life, people have less time for each work/task. This study focuses on knowing the factors that contribute to the buyer's willingness to wait and shop during the opening hours in the morning. A grocery store needs to focus well on the incremental efforts on enhancing the retail service quality of grocery store that helps to sustain and retain customers. Rarely, it so happens that the buyer needs to wait during the opening hours, as there is some delay in setting-up. The objective of this research is to predicting the factors that comforts the customer to wait at the grocery store during the delay in the setup. The key variable/factor that helps to predict is identified along with the category. Analysis helps to conclude that occupation motivates a customer to wait to shop and need to be empathic with them for sustenance.
\end{abstract}

Keywords: Retail Service Quality, Grocery store, Retail Store, Sustenance.

\section{INTRODUCTION}

The India retail report 2013 mentions that among all the retail categories, Mass Grocery Retail (MGR) is expected to outperform from 2013 to 2017 in terms of growth, forecasted an increase in sales by $107.9 \%$ [1]. The need to service the customers for sustainability in the latter years will arise, as the sales potential will attract more grocery retailers into the market. Measuring service quality is not easy due to its nature: Intangibility, heterogeneity, inseparability and Perishability [2]. Perception and expectation scores of each factor contributes to Service quality, the wider the gap in the score for perception and expectation the lesser is the service quality [3]. Based on this perspective, Parasuraman and his research team developed a scale for measuring service quality popularly known as SERVQUAL. Tangibility, reliability, responsiveness, assurance, and empathy are the five dimensions of service quality.

The researcher customized the items in the five dimensions to suit grocery retailing. Sustainability enhances service quality. Hence, the researcher attempts to predict the factor that motivates the shopper to wait during the store opening hours. The predictor variables are as follows: spending on grocery, frequency of grocery shopping, age, occupation. Identification of the factor(s) and the prediction of those who will wait to shop grocery pave way for sustenance.

Revised Manuscript Received on December 16, 2019.

* Correspondence Author

Dr. R. Ayyamperumal*, Department of Business Administration, Kalasalingam Academy of Research and Education, Krishnankovil, Tamilnadu, India.. Email: ayyamperumalr@klu.ac.in

Dr. B. SenthilArasu, Professor of Management Studies, National Institute of Technology, Tiruchirapalli, Tamilnadu, India. mail: tmbsenthilarasu@yahoo.co.in

\section{LITERATURE REVIEW}

Customer satisfaction or delight forms the base for revisit to a retail store. For instance, when a buyer is delighted with the way a private branded grocery is packed and delivered, it makes the buyer record as good product/store or service. As an outcome, the delighted buyers will be happy to share the experience with those in their reach. The truth is that "word-of-mouth" helps to achieve a majority percentage of sales. Even a small growth in customer retention can add around $25 \%$ of profit [4]. The University of Michigan in a research concluded that there is $2.37 \%$ increase in return on investment for each percentage increase in customer satisfaction [5]. Hence, sustainability plays a major role. In general, the buyers largely speak about the grocery store where they felt that they were serviced the way they wanted; these customers will happily come forward to offer higher price [6]. Consumer surplus plays a greater role in sustainability.

A customer's patience to wait during the delay in the opening of the store indicates that the customer is satisfied and those customers who are not prepared to wait doesn't mean they will not be loyal to in future, through quality and sustainability they might also become loyal in future. Having loyal customers is the base for a successful business, more importantly during the financial recession, which can adversely affect the performance of a business or might threaten the existence of a business [7]. Customer satisfaction is a "Golden egg laying Duck", they must be cared and maintained like an asset of the grocery store. This applies to any type of business or organizations [8].Strategies that are more effective are required to increase the Food \& Vegetable buying in grocery stores. Grass roots action involving specific strategies that enhance a sense of economy buying for low-income communities are key considerations to sustainability [9]. A conceptual framework on service quality to examine the impact of customer's participation in service delivery infers that for certain service that are familiar to consumers or the ones that require a low level of expertise is suggested to increased customer participation, thus it enhance service quality and sustainability [10].

In the past two decades, researchers have identified the core attributes of service quality, and devised a methodology to measure and stressed that to compete or sustain any organisation needs to know the customers' expectation and perception of service quality as these factors influences the customers' choice of store based on their comfort level. [11], [12], [13], [14]. 
Shopping orientation has an influence on the choice of channel in the French grocery [15].

\section{STATEMENT OF PROBLEM}

Due to the growth in the number of retail stores, the buyers prefer a better store that is assessable to them. Sometimes the main gate into the store is opened but the buyer has to wait as pre preparation is delayed. Some buyers move to another store. Hence, the researcher would like to predict the loyal customers who are willing to wait to shop during the store opening hours along with the factors that motivate a buyer to wait. This analysis aims at predicting the factors and the customers who will wait due to the delay in setup during the early hours to buy grocery. $65.5 \%$ (355) of the respondents answered "No" and 34.5\% (187) of the respondents answered "Yes" when they were asked whether they would wait to buy. This research predicts from both the category of respondents. Collected the research data from five major cities in Tamilnadu, India (Chennai, Salem, Trichy, Madurai, and Tirunelveli).

\section{RESEARCH OBJECTIVES}

This research plans to analyse the influence of the selected factors on customer's willingness to wait due to the delay in setup in early hours. The below are the specific objectives:

A. To determine the factors of prediction that decides the customer's willingness to wait to buy grocery due to the delay in setup during early hours using Binary Logistic Regression.

B. To predict the customers who will wait, the conversion from those who said they would wait and those who said they will not wait to shop grocery.

\section{METHODOLOGY}

Research is descriptive in nature. Descriptive method is a method that describes the study systematically, methodologically, rationally and ethically utilizing opinion, behavior and its relevance to the phenomenon being studied [16]. A structured questionnaire has five dimensions consisting of 22 items of SERVQUAL. Reliability and validity was tested. Since the population size of the grocery customers is not known the sampling method employed is convenience sampling. The sample size was arrived using the formula for unknown population. Confidence level was $98 \%$ with $5 \%$ margin of error and population proportion as $50 \%$. The calculated sample size was 543 . The researcher distributed 700 and 542 were usable questionnaires.

\section{A. Method of Analysis}

The researcher used Binary Logistic Regression to predict. The willingness of the customer to wait to buy grocery as dependent variable and the covariates/predictors are spending on grocery, frequency of grocery shopping, age, and occupation.

\section{RESULT AND DISCUSSION}

The result of the analysed data is tabulated as below for discussion.

\begin{tabular}{|l|l|r|r|c|}
\hline \multicolumn{5}{|c|}{ Table I: Omnibus Tests of Model Coefficients } \\
\hline \multicolumn{2}{|c|}{} & \multicolumn{1}{c|}{ Chi-square } & df & \multicolumn{1}{c|}{ Sig. } \\
\hline \multirow{3}{*}{ Step 1 } & Step & 36.109 & 8 & .000 \\
\cline { 2 - 5 } & Block & 36.109 & 8 & .000 \\
\cline { 2 - 5 } & Model & 36.109 & 8 & .000 \\
\hline
\end{tabular}

The Omnibus test of model coefficients is shown in table I. This is an indication that confirms whether the model with our independent variables fits well (i.e. whether it results in a better prediction) than the baseline model. The significance is shown in the final column of table 1 and is 0.000 (is less than $0.05)$ which confirms that this model is significant. It is evident that our model with the four predictors fits the best. It shows the goodness of fit which means that the prediction can be relied on.

\begin{tabular}{|l|c|r|c|}
\hline \multicolumn{4}{|c|}{ Table II: Hosmer and Lemeshow Test } \\
\hline Step & Chi-square & df & Sig. \\
\hline 1 & 9.273 & 8 & .320 \\
\hline
\end{tabular}

Table II shows the Hosmer and Leweshow test's chi-square value 9.273. A non-significant chi-square value 0.320 is a clear indication that the data fits the model well. This test had cleared the question regarding the goodness of fit. The significance value is greater than 0.05 , hence it fits well [17].

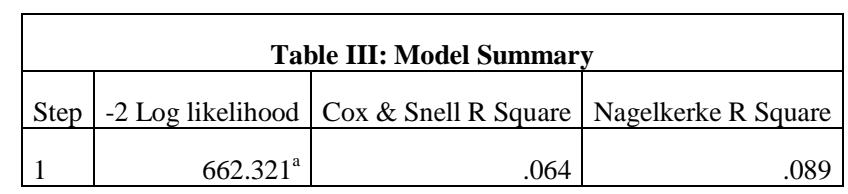

The Table III provides with the Pseudo R square statistics. The model summary has two measures, Cox \& Snell and Nagelkerke R Square. The formulas are different, but both the formula is valid. As in table 2, the Cox \& Snell's R square is 0.064 , and Nagelkerke $R$ square is 0.089 . These numbers indicate less improvement in fit over the baseline model (0-0.1 would indicate less improvement in fit and greater than 0.5 indicates high improvement in fit). The value shows that it does not largely contribute to the improvement of fit over the baseline model.

\begin{tabular}{|l|l|c|c|c|c|c|c|}
\hline \multicolumn{7}{|c|}{ Table IV: Variables in the Equation } \\
\hline \multicolumn{1}{|l}{$\begin{array}{l}\text { Step } \\
1^{\mathrm{a}}\end{array}$} & $\begin{array}{l}\text { On an average how } \\
\text { much do you spend in } \\
\text { grocery store per } \\
\text { month }\end{array}$ & .091 & .103 & .784 & 1 & .376 & 1.095 \\
\cline { 2 - 9 } & Age & .099 & .124 & .635 & 1 & .425 & 1.104 \\
\hline & Shopping Frequency & .079 & .094 & .714 & 1 & .398 & 1.083 \\
\hline & Occupation - Business & & & 30.143 & 5 & .000 & \\
\hline & $\begin{array}{l}\text { Occupation(1)- } \\
\text { Government }\end{array}$ & .143 & .389 & .135 & 1 & .714 & 1.154 \\
\cline { 2 - 8 } & $\begin{array}{l}\text { Occupation(2)- } \\
\text { Private }\end{array}$ & -1.700 & .471 & 13.015 & 1 & .000 & .183 \\
\cline { 2 - 8 } & $\begin{array}{l}\text { Occupation(3)- } \\
\text { Home maker }\end{array}$ & -.838 & .345 & 5.902 & 1 & .015 & .432 \\
\cline { 2 - 8 } & $\begin{array}{l}\text { Occupation(4) - } \\
\text { Student }\end{array}$ & -.566 & .386 & 2.152 & 1 & .142 & .568 \\
\hline
\end{tabular}




\begin{tabular}{|l|l|r|r|r|r|r|r|}
\hline & $\begin{array}{l}\text { Occupation(5) - } \\
\text { Professional }\end{array}$ & -1.042 & .445 & 5.483 & 1 & .019 & .353 \\
\cline { 2 - 8 } & Constant & -.544 & .477 & 1.301 & 1 & .254 & .580 \\
\hline
\end{tabular}

a. Variable(s) entered on step 1: On an average how much do you spend in grocery store per month, Age, Shopping Frequency, Occupation.

The above table IV shows the variables in the equation. It predicts the factors/variables that enhance the prediction of the respondents willing to wait to buy grocery due to delay in setup during the early hours. Below is the Eq (1) that is used to calculate the probability value. The " $\mathrm{B}$ " value refers to the coefficient of the constant and is known as "intercept".

Binary Logistic Regression equation

$$
\begin{aligned}
&=\alpha+\beta_{1} X_{1}+\beta_{2} X_{2}+\beta_{3} X_{3}+\beta_{4} X_{4} \text { (1) } \\
&=-0.544+ 0.091 \text { (Spending on Grocery) }+ \\
& 0.099 \text { (Age) }+0.079 \text { (Shopping } \\
& \text { frequency) }+(-1.042) \text { (Occupation) }
\end{aligned}
$$

Alpha $(\alpha)$ in the equation (1) indicates the constant as in column one of table 4 . The "B" $(\beta)$ values are shown in column two of the table 4 for the respective variables.

\begin{tabular}{|c|c|c|c|c|c|}
\hline \multicolumn{6}{|c|}{ Table V: Classification Table ${ }^{\mathrm{a}}$} \\
\hline & \multirow{3}{*}{\multicolumn{2}{|c|}{ Observed }} & \multicolumn{3}{|c|}{ Predicted } \\
\hline & & & \multicolumn{2}{|c|}{$\begin{array}{c}\text { Will Wait to } \\
\text { purchase grocery } \\
\text { during the early in the } \\
\text { Morning? }\end{array}$} & \multirow{2}{*}{$\begin{array}{c}\text { Percentage } \\
\text { Correct }\end{array}$} \\
\hline & & & No & Yes & \\
\hline \multirow{3}{*}{$\begin{array}{l}\text { Step } \\
1\end{array}$} & \multirow{2}{*}{$\begin{array}{l}\text { Will Wait to purchase } \\
\text { grocery during the } \\
\text { early hours in the } \\
\text { Morning? }\end{array}$} & No & 308 & 47 & 86.8 \\
\hline & & Yes & 136 & 51 & 27.3 \\
\hline & \multicolumn{2}{|l|}{ Overall Percentage } & & & 66.2 \\
\hline
\end{tabular}
The significance is below 0.05 for the variable occupation hence the variable "occupation" contributes to the prediction model [18].

The cut-off value should be greater than or equal to 0.5 to predict that the respondent will wait to buy grocery in the early hours. Those respondents with a cutoff value less than 0.5 are predicted as those who are not willing to wait and buy grocery during the early hours.

The classification table V shows the predicted result along with the observed frequency. From the table predicted that among 355 respondents who had said that they will not wait (observed), predicted that 47 respondents might have the willingness to wait to buy grocery. The correctness of the predicted percentage for "No" is $86.8 \%$. Among 187 respondents (observed) who said that they would wait to buy grocery, predicted that 51 respondents might wait to buy grocery. The correctness of the predicted percentage for "Yes" is $27.3 \%$. Based on the four predictors using binary logistic regression predicted that 98 respondents (observed 187) out of 542 have the willingness to wait due to setup delay to buy grocery during the early hours in the morning.
Table VI: Predicted group * Willingness to wait due to delay in setup to buy grocery * Occupation

Cross tabulation

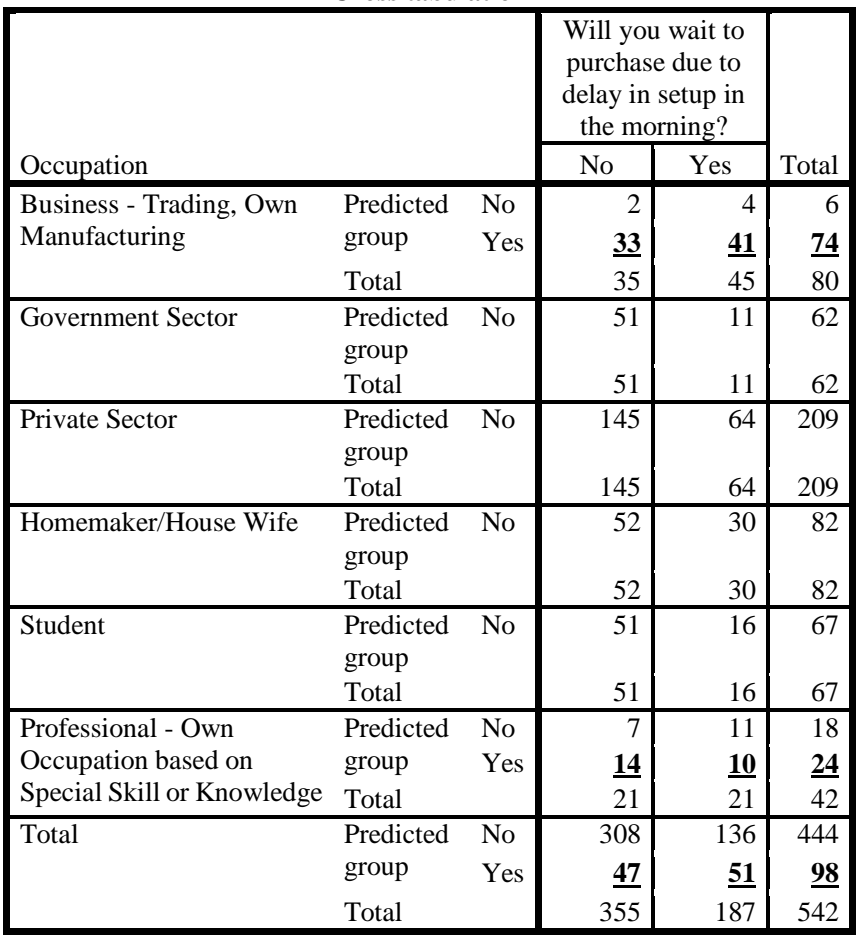

Based on the results obtained from table 6, the following are the conclusions:

A.Predicted the variable that contributes to the prediction regarding the willingness to wait, found that "occupation" is the only factor that contributes to the respondent's decision on the willingness to wait, is logically correct too. People of different occupation have different urgency or time flexibility. Respondents who are professional or businessperson are predicted to have the willingness to wait to buy. People with these two occupation has flexibility in time or these type of people are choosy and generally do not compromise on the quality of grocery buying. Hence these category of respondents would even wait to buy.

B. Among 355 respondents those who had said they will not wait, 47 respondents might have the intention to wait as per the prediction. Among 187 respondents who said that they would wait to buy grocery, only 51 respondents might wait as per prediction. Based on the analysis using four predictors, predicted that 98 respondents have the intention to wait. Hence, it is clear that the predicted conversion from the analysis, among those who said yes and no.

\section{CONCLUSION}

The food-based grocery stores are at the forefront of the movement in USA. Presently, the trend in USA is towards zero waste models, grocers had started to step-in to provide sustainably sourced grocery and ethically traded green grocery that are as good for the planet as those who consume them [19]. Hence, the researcher suggests the same for the grocery store for sustainability.

Published By: 
Based on the four predictors using binary logistic regression, the researcher predicted 98 respondents out of 542 have the willingness to wait due to setup delay to buy grocery during the early opening hours in the morning. Hence, sustenance is possible. This shows that sustenance is possible through continuous better service that makes them wipe other choice of grocery stores. Therefore, the store should focus on business people and professionals who have flexibility in time and posses patience.

\section{REFERENCES}

[1] I. B. M. I. S. Forecasts, "INDIA RETAIL REPORT Q1 2013," 2013.

[2] Bateson, "SERVQUAL: Review, critique, research agenda," Eur. J. Mark., vol. 30, no. 1, pp. 8-32, 1995.

[3] Parasuraman.A, Zeithaml.A, and Berry.L, "SERVQUAL: A Multiple-Item Scale for Measuring Consumer Perceptions of Service Quality," J. Retail., vol. 64, no. 1, 1988.

[4] C. N. K. Naik, S. B. Gantasala, and G. V. Prabhakar, "Service Quality (Servqual) and its Effect on Customer Satisfaction in Retailing," Eur. J. Soc. Sci., vol. 16, no. 2, pp. 231-243, 2010.

[5] T. L. Keiningham and T. G. Vavra, The customer delight principle: Exceeding customers' expectations for bottom-line success. Chicago: McGraw-Hill, 2001.

[6] J. Anselmsson, U. Johansson, and N. Persson, "Understanding price premium for grocery products : a conceptual model of customer-based brand equity," Brand, 2004

[7] N. Tsolakis, "Entrepreneurial Prospects in Loyalty Marketing: Real-world Grocery Retailers' Market Survey \& Conceptual Case Study," Procedia - Soc. Behav. Sci., vol. 175, pp. 3-11, Feb. 2015.

[8] G. S. Sureshchandar, C. Rajendran, and T. J. Kamalanabhan, "Customer perceptions of service quality: A critique," Total Qual. Manag., vol. 12, no. 1, pp. 111-124, 2001.

[9] K. Glanz and A. L. Yaroch, "Strategies for increasing fruit and vegetable intake in grocery stores and communities: policy, pricing, and environmental change," Prev. Med. (Baltim)., vol. 39, pp. 75-80, 2004.

[10] P. A. Dabholkar, D. I. Thorpe, and J. O. Rentz, "A Measure of Service Quality for Retail Stores: Scale Development and Validation," J. Acad. Mark. Sci., vol. 24, no. 1, pp. 3-16, Dec. 1995.

[11] C. Grönroos, "A Service Quality Model and its Marketing Implications," Eur. J. Mark., vol. 18, no. 4, pp. 36-44, 1984.

[12] A. Parasuraman, V. Zeithaml, and L. Berry, "A conceptual model of service quality and its implications for future research," J. Mark., vol. 49, no. 4, pp. 41-50, 1985.

[13] J. J. Cronin and S. a Taylor, "Measuring Quality: A Reexamination and Extension," J. Mark., vol. 56, no. 3, pp. 55-68, 1992.

[14] R. K. Teas, "Expectations, Performance Evaluation, and Consumers' Perceptions of Quality," J. Mark., vol. 57, no. 4, p. 18, Oct. 1993.

[15] M. C. Cervellon, J. Sylvie, and P. V. Ngobo, "Shopping orientations as antecedents to channel choice in the French grocery multichannel landscape," J. Retail. Consum. Serv., vol. 27, pp. 31-51, Nov. 2015.

[16] R. Ayyamperumal, "Research methodology - Research types," Google Drive, 2015.2 [Online]. Available: https://drive.google.com/open?id=1sKhveHrEvqCMcYI_BRbZAhtT HI190X7z1o-0Y61KK7w.

[17] F. C. Pampel, Logistic Regression: A Primer, Illustrate. NEWDelhi: SAGE Publications, 2000.

[18] A. Field, Discovering Statistics Using SPSS, 3rd ed. NEWDelhi: SAGE Publications, 2007.

[19] Amiel, "21 American Grocery Stores Committed to Sustainability," Rosseto Serving Solutions. [Online]. Available: https://www.rosseto.com/blog/sustainability/. [Accessed: 04-Jul-2019].

\section{AUTHORS PROFILE}

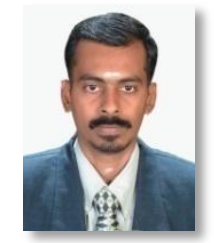

Dr. R.Ayyamperumal completed his bachelor's degree in Commerce and master's in Business Administration. He had completed Post Graduate Diploma(s) in International Business, Computer Applications, Retail Management, and M.Phil. in Management. He cleared UGC-NET in Management and has teaching experience of 19 years. He had attended thirty workshops/conferences/seminars, among these two at IIM-B, two at
IIM-K and one at IIM-C. Presented six papers in International conference and 16 papers in National and Regional conferences/seminars. Published Three papers in International and National journal. His learning spirit made him learn SPSS, AMOS and Smart PLS. He had organised programs on "Literature Review and Application of statistics in research". He is a trainer in soft skills and in other areas of organisational behaviour. He is a Life member in VIDITISIA, Virudhunagar

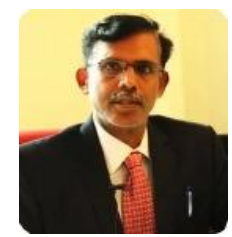

Dr. B.SenthilArasu, an Electronics and Communication Engineer completed his master's in Business Administration and then his doctorate in the area of stock price behavior. Has a total experience of twenty-one years, of which a considerable period of time was spent in the industry. Worked as an equity research analyst and then switched to academics. He has a rich academics experience, currently working as a Professor at National Institute of Technology, Trichy. Offering a variety of electives like Business analysis and IT consulting in Capital Market, Financial Risk Analytics, and Personal Finance, etc. he also held the post of Associate Dean (Institute Development). All along with his academic career, he has been very much interested in offering consultancy and also conducting Management Development Program for corporate executives. He has been conducting Management Development Program to various organizations like, Tamilnadu Newsprint Limited, BHEL, NLC, L\&T and various other small and medium enterprises. He has offered MDP's in areas like Finance for non-finance executives, emerging areas in Cost accounting and Project financing, Risk Management, Problem-solving skills, Creativity and Innovation, Personal Finance, etc. He was a Co-Investigator for a UKIERI sponsored project titled Building Management Capabilities in SME's across the country. He has published papers in International Journals with impact factor and also a Recognized Guide and Examiner and Board of Studies Member under various Universities. His current research includes stock price prediction using data mining techniques, Equity crowd funding, Performance Management of SMEs. 